\title{
REKAYASA ALAT PENYEHATAN UDARA RUANGAN \\ UNTUK MENURUNKAN KADAR GAS KARBONMONOKSIDA (CO)
}

Chandra Pratama, Imam Khambali, Suprijandani

\begin{abstract}
The concentration of air pollutants inside houses is greater than those outside of houses and most pollutants consisted of carbon monoxide (CO)-containing combustion gases that are harmful to health. It is quite necessary to innovate air control through engineering procedures such as room air sanitizing devices to lower the $\mathrm{CO}$ level. The purpose of the study was to determine the effectiveness of a room air-sanitizing device in reducing the levels of $\mathrm{CO}$ gases.

The study was considered as pre-experimental fashioned in a one-group pre-post test design. The independent variable was the room air-sanitizing device and the dependent variable was $\mathrm{CO}$ concentration. Data was analyzed using paired $t$-tests.

Results showed that there was a reduction in $\mathrm{CO}$ of $185.3 \mathrm{ppm}$ after passing it throligh the room air-sanitizing device set at a suction flow rate of $2.2 \mathrm{It} / \mathrm{min}$ resulting in reduction of $73.9 \%$. Paired $t$ tests showed a $P=$ $0.013<\sigma(0.05)$, indicating that there was a significant difference in CO reduction after passing through the device. A room sanitizing device is said to be effective when the characteristics and the mass of the activated carbon are the same, the contact time of the adsorbate and adsorbent is sufficiently long and the rate of CO reduction $\geq 50 \%$ of the initial levels.

In conclusion, there was a significant reduction in $\mathrm{CO}$ after passing through a room air-sanitizing device. However, the reduction could only effectively occur for less than 21 hours. It is recommended to examine other specifications of the actived carbon such as the surface area, density, porosity, and component composition in order to determine factors that contribute to the differences. Additionally, it is recommended to engineer device with a simpler design.
\end{abstract}

Keywords $\quad: \mathrm{CO}$, activated carbon, adsorption, room air

\section{PENDAhuluan}

Pencemaran udara adalah kehadiran satu atau lebih substansi fisik, kimia, atau biologi di atmosfer dalam jumlah yang membahayakan kesehatan manusia, hewan dan tumbuhan, mengganggu estetika dan kenyamanan, atau merusak properti (EPA dalam Nurbiantara, Setiyawan, 2009). Permasalahan dalam pencemaran udara dalam ruangan yang utama adalah konsentrasi polutan lebih banyak terdapat di dalam rumah (indoor) daripada di luar ruangan (Department of Health Minnesota dalam Saragih, Winda, 2011). Ario Guritno (2012), menyatakan bahwa polutan udara ruang banyak ditemukan dari asap hasil pembakaran yang mengandung gas karbondioksida (CO2) sebagai hasil pembakaran tidak sempurna.

Menurut Permenkes No.1077 tahun 2011, upaya penyehatan udara dalam ruang meliputi substansi fisik, kimia, dan biologi. Substansi kimia yang salah satu sumber pencemarnya adalah gas $\mathrm{CO}$, sangat perlu dilakukan upaya penyehatan, mengingat kualitas udara yang tidak memenuhi persyaratan kimia, dapat menimbulkan dampak kesehatan yang cukup serius. Salah satu upaya memperbaiki kualitas udara ruangan adalah dengan menciptakan suatu rekayasa alat penyehatan udara ruangan untuk menurunkan kadar gas $\mathrm{CO}$.

Perumusan masalah adalah apakah alat penyehatan udara ruangan dapat menurunkan kadar gas $\mathrm{CO}$ di dalam ruangan. Sedangkan tujuannya adalah untuk mengetahui efektivitas alat penyehatan udara ruangan dalam menurunkan kadar gas $\mathrm{CO}$.

\section{METODA PENELITIAN}

Penilitian ini merupakan penilitian pra eksperimen dengan bentuk One Group Pretest Posttest Design, yaitu rancangan yang dilakukan pada observasi pertama (pretest) untuk menguji perubahan-perubahan yang terjadi setelah adanya eksperimen (Notoatmodjo, 2012:57).Objek penelitian adalah gas $\mathrm{CO}$ yang berasal dari asap hasil pembakaran rokok. Pengambilan sampel dengan pertimbangan waktu, kemampuan, dan kebutuhan peneliti, sehingga pengukuran dilakukan sebanyak 10 kali untuk mengetahui rata-rata kadar gas $\mathrm{CO}$. Pengumpulan data berupa observasi, pengukuran, dan sampling udara.

Analisis data menggunakan uji paired $t$ test, dimana paling umum dikenal dengan pre-post test, artinya membandingkan rata-rata nilai pre test dan rata-rata post test dari suatu sampel. 


\section{ALAT DAN BAHAN PENELITIAN}

a. Gas Alert Micro Clip XT

b. FlowMeter

c. Stopwatch

d. Mesh ukuran 120 dan kuas Meja

e. Akrilik (Ketebalan $0.3 \mathrm{~cm}$ dan $0.5 \mathrm{~cm}$ )

f. BOSS Portable Battery Pump New - 2

g. Power supply

h. Karbon aktif Tempurung Kelapa

i. Rokok

j. Battery (ABC size $1,5 \mathrm{~V})$

\section{PROSEDUR REKAYASA ALAT}

1. Siapkan alat dan bahan

2. Merangkai sesuai dengan bagan pada Gambar 1

3. Lakukan proses pengujian kebocoran dengan cara memasukkan air ke dalam alat

4. Apabila sudah tidak ada kebocoran, maka dilanjutkan ke tahap selanjutnya sedangkan apabila masih terjadi kebocoran maka dilakukan perbaikan
5. Pasang Boss Portable Battery Pump New-2 pada tempat yang sudah disediakan pada alat yaitu di ruang Vacum

6. Pasang selang untuk menghisap dan mengeluarkan udara

7. Rangkai susunan kabel tembaga dan power supply yang berada di ruang vacum untuk dihubungkan ke bagian alat pump yang berfungsi

8. Masukkan karbon aktif yang sudah di aktivasi

9. Masukkan kabel ke stop kontak sebagai penghubung untuk sumber energi atau dapat pula menggunakan baterai yang sebelumnya terpasang pada alat pump sebagai pengganti sumber energi dari listrik secara langsung

10. Terdapat saklar yang berfungsi sebagai media untuk menghidupkan dan menyalakan alat

11. Alat Penyehatan Udara untuk Menurunkan Kadar Gas Karbonmonoksida (CO) secara visual dicat berwarna hitam dan alat telah siap digunakan

Gambar 1. Desain Alat

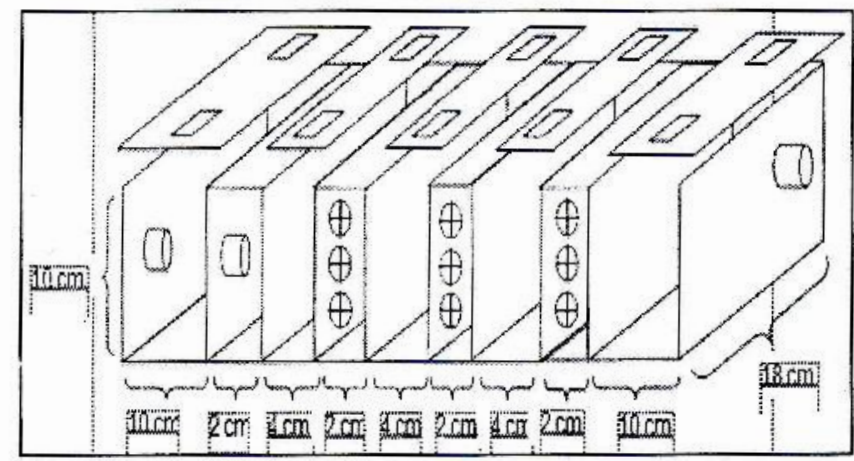

\section{PROSEDUR KERJA ALAT}

1. Persiapkan alat

2. Masukkan karbon aktif yang sebelumnya telah diaktivasi

3. Alat yang sudah siap digunakan diletakkan pada tripot yang sudah disiapkan

4. Masukkan kabel penghubung alat ke stop kontak

5. Hidupkan alat tersebut melalui saklar

6. Paparkan alat tersebut dalam ruangan

\section{PROSEDUR PENGUKURAN GAS CO}

1. Siapkan alat dan bahan untuk mengukur kadar gas $\mathrm{CO}$

2. Ambil alat pengukur $\mathrm{CO}$ yaitu Gas Alert Micro Clip XT

3. Ukur kadar gas CO yang berada pada replika ruangan dengan cara memasukkan alat pengukur ke dalam replika ruangan dan catat hasil yang tertera

\section{HASIL DAN PEMBAHASAN}

Prosedur preparasi karbon aktif dengan melalui pemilihan bahan berupa tempurung kelapa, ukuran butiran 125 um, dan perlakuan pencucian serta pemanasan dengan oven pada suhu $120^{\circ} \mathrm{C}$ selama 24 jam. Menurut Maryanto, Dicky (2009), karbon aktif merupakan adsorben yang memiliki pori-pori diameter yang sangat kecil yang dapat menyerap gas, sehingga gas $\mathrm{CO}$ yang melewatinya akan terikat dan mengalami gaya tarik menarik dengan pori-pori karbon aktif. Sehingga menggunakan ukuran butiran sebesar 125 um.

Karbon aktif yang sudah memenuhi standar ukuran yang akan menjadi adsorben untuk menurunkan kadar gas $\mathrm{CO}$ dicuci untuk menghilangkan kadar abu karena abu yang berlebihan akan menyebabkan terjadinya penyumbatan pori arang aktif sehingga luas permukaan aktif menjadi berkurang. Selanjutnya, karbon aktif dipanaskan dengan oven. 
Menurut Basuki, Tri Kris (2008) karbon aktif dari arang tempurung kelapa mengandung ion-ion logam dan molekul-molekul air. Dalam keadaan normal ruang antar-lapis pada arang tempurung kelapa terisi oleh molekul air bebas yang berada di sekitar kation. Bila arang tempurung kelapa dipanaskan sampai pada suhu $100{ }^{\circ} \mathrm{C}$ maka molekul-molekul air akan menguap, sehingga arang tempurung kelapa dapat berfungsi sebagai penyerap gas. Tetapi apabila arang tempurung kelapa dipanaskan di atas $150^{\circ} \mathrm{C}$, struktur arang tempurung kelapa tersebut akan rusak karena tidak tahan panas. Oleh karena itu, penentuan suhu oven sebesar $120{ }^{\circ} \mathrm{C}$ dalam memanaskan karbon aktif dilakukan agar penguapan molekul air dapat berjalan optimal dan mampu menghindarkan kerusakan struktur karbon aktif. Waktu pemanasan dalam oven dilakukan selama 24 jam agar dapat menguap dan kelembapannya juga menjadi rendah secara keseluruhan (homogen). Sehingga didapatkan persentase penurunan pada tabel dibawah ini :

Tabel 1: Persentase penurunan berat karbon aktif

\begin{tabular}{|c|c|c|c|c|c|}
\hline No. & $\begin{array}{c}\text { Berat } \\
\text { Petridisk }\end{array}$ & $\begin{array}{c}\text { Berat Awal } \\
\text { Karbon Aktif }\end{array}$ & $\begin{array}{l}\text { Berat Akhir } \\
\text { Karbon Aktif }\end{array}$ & $\begin{array}{c}\text { Selisih } \\
\text { Penurunan }\end{array}$ & $\begin{array}{l}\text { Persentase } \\
\text { Penurunan }\end{array}$ \\
\hline 1. & $96,4 \mathrm{gr}$ & $10 \mathrm{gr}$ & $9,1 \mathrm{gr}$ & $0,9 \mathrm{gr}$ & $9 \%$ \\
\hline 2. & $55,2 \mathrm{gr}$ & $10 \mathrm{gr}$ & $9,4 \mathrm{gr}$ & $0,6 \mathrm{gr}$ & $6 \%$ \\
\hline 3. & $95,6 \mathrm{gr}$ & $10 \mathrm{gr}$ & $9,3 \mathrm{gr}$ & $0,7 \mathrm{gr}$ & $7 \%$ \\
\hline \multirow{2}{*}{\multicolumn{4}{|c|}{ Jumlah }} & $2,2 \mathrm{gr}$ & $22 \%$ \\
\hline & & Rata-rata & & $0,73 \mathrm{gr}$ & $7,3 \%$ \\
\hline
\end{tabular}

Berdasarkan Tabel 1 diatas, penurunan terjadi sebesar 7,3 \% dari berat awal. Menurut Meisrilestari, Yessy (2013), terjadinya perubahan massa disebabkan pada proses pemanasan terjadi pembentukan dan penyusunan arang, sehingga pori-pori akan menjadi besar yang mengakibatkan berat arang menjadi berkurang karena poriporinya sudah tidak rapat seperti sebelum proses aktivasi (pemanasan).
Pengukuran terhadap kemampuan aliran hisap vacum udara ditinjau dari sumber energi, yaitu sumber energi utama (AC) dan sumber energi alternatif (baterai). Kedua sumber energi ini mempunyai kemampuan hisap sama yaitu sebesar $2,2 \mathrm{lt} /$ menit dengan tegangan 3 volt. Namun sumber energi alternatif mempunyai kemampuan optimum yang ditunjukkan pada grafik di bawah ini :

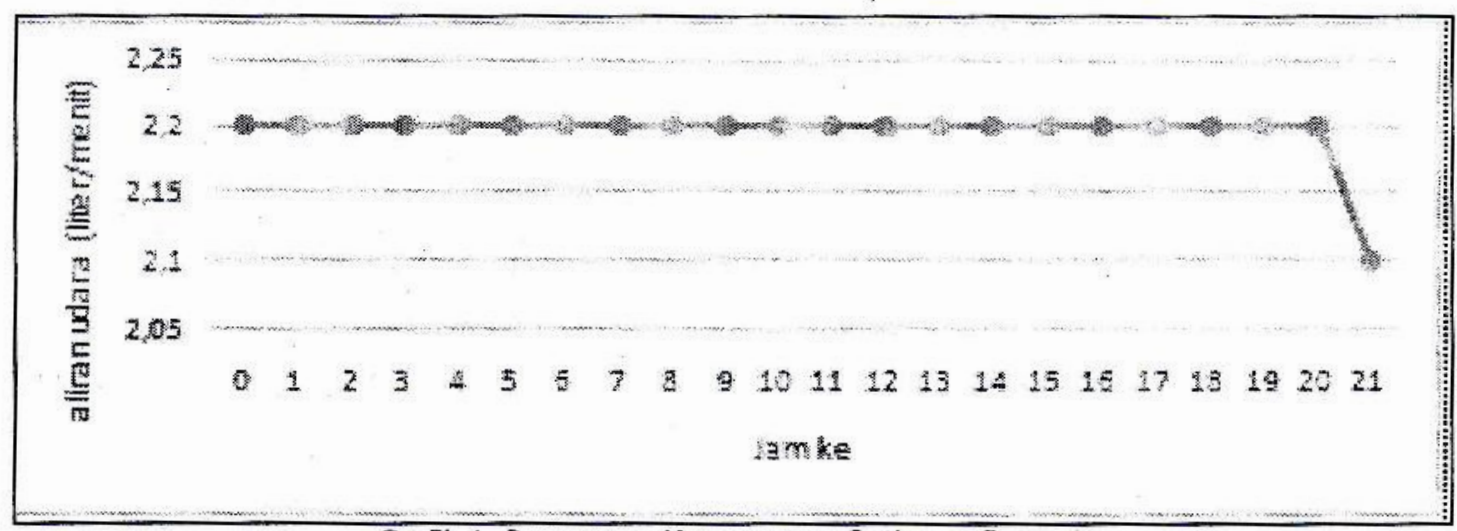

Grafik 1. Penurunan Kemampuan Optimum Baterai

Berdasarkan Grafik 1 diatas, penurunan terjadi pada jam ke 21. Sehingga batas optimum baterai yang digunakan penelitian ini sebesar $20 \mathrm{jam}$. Hal ini dikarenakan selama pemakaian, seng secara perlahan-lahan larut ketika arus listrik dihasilkan. Ketika ammonium khlorida jenuh, aliran arus listrik berhenti dan sel harus dibuang. Sel seperti itu dikatakan primer atau tak dapat diisi ulang (Departemen Teknik Kimia ITS, 2013).

Dari hasil penelitian yang sudah dilakukan, penurunan kadar gas CO dapat diketahui melalui tabel yang berada di bawah ini: 
Tabel 2: Persentase Penurunan Kadar Gas CO

\begin{tabular}{|c|c|c|c|c|}
\hline \multirow{2}{*}{ No. Uji } & \multicolumn{2}{|c|}{ Hasil kadar gas CO } & $\begin{array}{c}\text { Selisih } \\
\text { Penurunan }\end{array}$ & $\begin{array}{c}\text { Persentase } \\
\text { Penurunan }\end{array}$ \\
\cline { 2 - 3 } & Pre test & Post test & $201 \mathrm{ppm}$ & $83,4 \%$ \\
\hline 1. & $241 \mathrm{ppm}$ & $40 \mathrm{ppm}$ & $208 \mathrm{ppm}$ & $75,36 \%$ \\
\hline 2. & $276 \mathrm{ppm}$ & $68 \mathrm{ppm}$ & $203 \mathrm{ppm}$ & $78,68 \%$ \\
\hline 3. & $258 \mathrm{ppm}$ & $53 \mathrm{ppm}$ & 203 & $74,15 \%$ \\
\hline 4. & $267 \mathrm{ppm}$ & $69 \mathrm{ppm}$ & $198 \mathrm{ppm}$ & $78,48 \%$ \\
\hline 5. & $257 \mathrm{ppm}$ & $81 \mathrm{ppm}$ & $176 \mathrm{ppm}$ & $68,48 \%$ \\
\hline 6. & $273 \mathrm{ppm}$ & $94 \mathrm{ppm}$ & $179 \mathrm{ppm}$ & $65,56 \%$ \\
\hline 7. & $276 \mathrm{ppm}$ & $80 \mathrm{ppm}$ & $196 \mathrm{ppm}$ & $71,01 \%$ \\
\hline 8. & $207 \mathrm{ppm}$ & $50 \mathrm{ppm}$ & $157 \mathrm{ppm}$ & $75,84 \%$ \\
\hline 9. & $222 \mathrm{ppm}$ & $49 \mathrm{ppm}$ & $173 \mathrm{ppm}$ & $77,92 \%$ \\
\hline 10. & $224 \mathrm{ppm}$ & $62 \mathrm{ppm}$ & $162 \mathrm{ppm}$ & $72,32 \%$ \\
\hline Jumlah & $2501 \mathrm{ppm}$ & $646 \mathrm{ppm}$ & $1853 \mathrm{ppm}$ &. \\
\hline Rata-rata & $250,1 \mathrm{ppm}$ & $64,6 \mathrm{ppm}$ & $185,3 \mathrm{ppm}$ & $74,27 \%$ \\
\hline
\end{tabular}

Berdasarkan Tabel 2 diatas, dapat diketahui bahwa rata-rata selisih penurunan kadar gas $\mathrm{CO}$ pada alat penyehatan udara ruangan sebesar $185,3 \mathrm{ppm}$. Sedangkan rata-rata persentase penurunan sebesar $74,27 \%$. Di bawah ini grafik persentase penurunan kadar gas $\mathrm{CO}$ pada alat penyehatan udara ruangan:

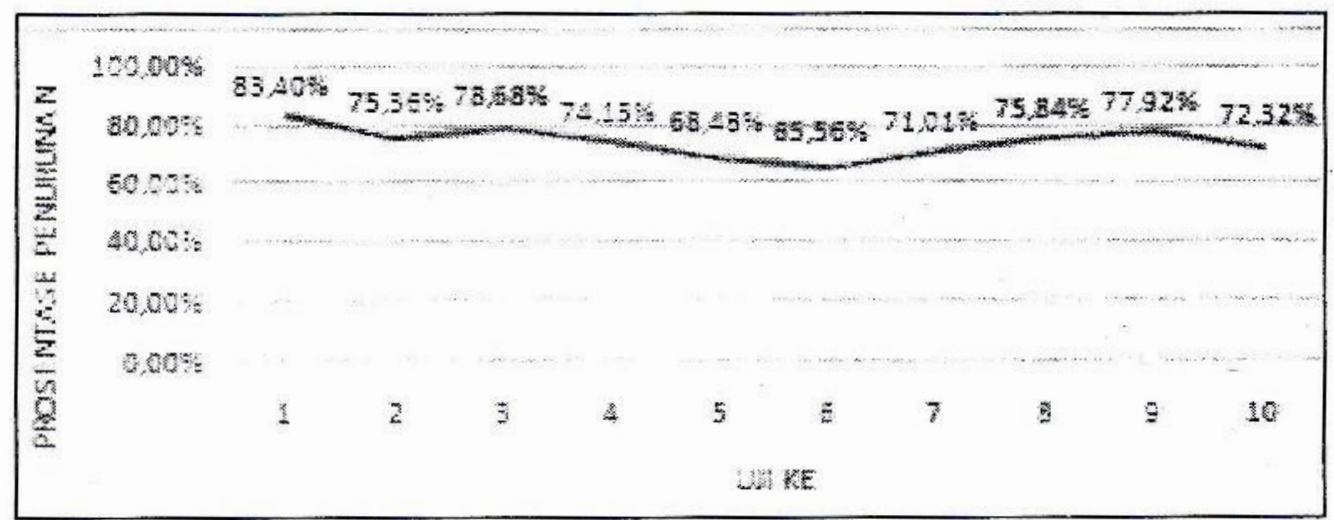

Grafik 2. Penurunan Kadar Gas CO Setelah Melalui Alat

Berdasarkan Grafik 2 diatas, dapat diketahui bahwa persentase penurunan kadar gas $\mathrm{CO}$ pada alat penyehatan udara ruangan menurun dari uji ke 1 hingga uji ke 2, yang kemudian meningkat kembali 1 tingkat pada uji ke 3 . Penurunan terjadi pada uji ke 6 dan kembali meningkat hingga uji ke 9 dan mengalami penurunan pada uji ke 10 . Persentase penurunan kadar gas $\mathrm{CO}$ pada alat penyehatan udara ruangan tertinggi persentasenya pada uji ke $1(83,40 \%)$, sedangkan penurunan terrendah pada uji ke 6 $(65,56 \%)$. Pada uji Paired t test diperoleh hasil p $=0.013<a(0.05)$ yang menunjukkan bahwa ada perbedaan penurunan secara signifikan antara kadar gas $\mathrm{CO}$ sebelum dan sesudah melalui alat penyehatan udara ruangan.

Penurunan kadar gas CO ini dikarenakan terjadi proses adsorpi dimana partikel menempel pada suatu permukaan akibat adanya perbedaan muatan lemah diantara kedua benda, sehingga membentuk suatu lapisan tipis partikel-partikel halus pada permukaan tersebut (Reynold, 1982 dalam Basuki, Tri Kris, 2008). Meilita S (2003) dalam Dunggio, Yusuf Muhammad (2012:19) menjelaskan bahwa karbon aktif adalah bahan berupa karbon bebas atau arang yang telah dibuat dan diolah secara khusus melalui proses aktifasi, sehingga pori-porinya terbuka dan dengan demikian mempunyai daya serap yang besar terhadap fase gas. Selain itu, daya serap juga ditentukan oleh luas permukaan partikel, dimana kemampuan ini menjadi lebih tinggi jika dilakukan aktifasi melalui pemanasan pada temperatur tinggi (Sembiring dan Sinaga, 2003 dalam Somad, Raden, 2009). Sedangkan menurut Agusta, Diana, (2012) bahwa semakin banyak massa adsorben yang digunakan, akan membuat jumiah partikel yang kontak dengan gas CO semakin banyak sehingga semakin banyak pula partikel gas $\mathrm{CO}$ yang teradsorp. 
Efektivitas alat penyehatan udara ruangan ditinjau dari hasil sebelum (pre) dan sesudah (post) perlakuan. Data pada Tabel 2 dan uji paired t test menunjukkan hasil penurunan secara signifikan dalam mengurangi kadar gas CO dalam ruangan. Selain itu, kriteria untuk dapat dikatakan efektif yaitu sebagai berikut:

1. Karakteristik dan Massa Karbon Aktif Sama Karateristik dan massa karbon aktif yang digunakan harus sesuai standar awal pada tahap preparasi sampel. Hal ini akan menentukan kemampuan karbon aktif dalam bereaksi pada gas $\mathrm{CO}$ pada masing-masing reaktor.

2. Waktu Kontak Adsorbat (Gas CO) dengan Adsorben (Karbon Aktif) Cukup Lama

Adsorben berupa karbon aktif ini mempunyai masa jenuh yang akan mempengaruhi kecepatan dalam kontak dengan adsorbat. Kapasitas adsorben akan jenuh seiring dengan bertambahnya waktu karena telah banyaknya adsorbat yang menempel pada adsorben (Basuki, Tri Kris, 2008). Pada saat terjadi kesetimbangan, semua bagian pada permukaan adsorben telah terisi oleh partikel adsorbat (Sukir, 2008). Sehingga adsorbat hanya akan melewati adsorben saja karena adsorben sudah tidak mampu mengadsorp gas $\mathrm{CO}$.

3. Mampu menurunkan kadar gas $\mathrm{CO} \geq 50 \%$ dari kadar awal

Ini dikarenakan fungsi dan tujuan utama pada alat ini yaitu sebagai penurun kadar gas $\mathrm{CO}$ dalam ruangan. Penurunan kadar gas CO melalui alat penyehatan udara ruangan ini harus terjadi secara signifikan yaitu $\geq 50$ $\%$ dari kadar awal gas CO sebelum melalui alat ini. Sehingga apabila penurunan tidak mampu terjadi secara signifikan yaitu $\geq 50$ $\%$ maka alat penyehatan udara ruangan ini kurang dapat digunakan secara efektif.

\section{KESIMPULAN}

1. Rata-rata kadar gas CO sebelum melalui alat penyehatan udara ruangan sebesar 250,1 ppm dan rata-rata sesudah melalui alat penyehatan udara ruangan sebesar ppm $64,6 \mathrm{ppm}$.

2. Terjadi penurunan kadar gas $\mathrm{CO}$ dengan persentase penurunannya sebesar $74,27 \%$.

3. Alat penyehatan udara ruangan ini ternyata efektif menurunkan kadar gas $\mathrm{CO}$ dengan kriteria selisih penurunan sebesar 185,3 ppm.

4. Kemampuan alat penyehatan udara ruangan untuk menurunkan kadar gas CO ditinjau dari kemampuan vacum udara yang menggunakan 2 sumber energi listrik ( 3 volt) dengan kemampuan aliran udara sebesar 2,2 It/menit, kemampuan karbon aktif sebagai media adsorben yang menurun $<50 \%$ pada jam ke 21, serta kemampuan alat terhadap ruangan yang dimana semakin besar ruangan untuk diuji maka semakin lama pula detensi waktu yang dicapai untuk menghisap gas $\mathrm{CO}$

\section{SARAN}

1. Pemeriksaan terhadap karateristik karbon aktif sebagai media adsorben lebih dilengkapi, berupa luas permukaan, densitas, kelembapan, porositas dan komposisi penyusun karbon aktif

2. Perlu dicoba karbon aktif selain menggunakan arang tempurung kelapa sebagai media adsorben.

3. Dilakukan perbandingan terhadap massa dan ukuran butiran karbon aktif yang digunakan sebagai media adsorben

4. Penggunaan vacum udara yang dapat diinovasi lebih luas lagi.

5. Perancangan desain alat yang lebih sederhana dan lebih efisien.

6. Pengujian dilakukan lebih lama, hingga ditemukan kadar gas $\mathrm{CO}$ pada effluen dikatakan aman bagi manusia sesuai dengan peraturan yang berlaku.

\section{DAFTAR PUSTAKA}

Agusta, Diana, 2012. Uji Adsorpsi Gas CO pada Asap Kebakaran dengan Menggunakan Karbon Aktif dari Arang Tempurung Kelapa yang Terimpregnasi $\mathrm{TiO}_{2}$.Depok, Program StudiTeknik Kimia, FT-UI.

Basuki, Tri Kris, Setiawan, Budi, dan Nurimaniwathy, 2008. Penurunan Konsentrasi $\mathrm{CO}$ dan $\mathrm{NO}_{2}$ pada Emisi Gas Buang Menggunakan Arang Tempurung Kelapa yang Disisipi $\mathrm{TiO}_{2}$. Yogyakarta, Sekolah Tinggi Teknologi Nuklir-BATAN.

Departemen Teknik Kimia ITS, 2013.Baterai Dan Jenisnya .http://elkimkor.com/2013/01/04/bateraidan-jenisnyal, 9 Agustus 2014.

Dunggio, Yusuf Muhammad, 2012. Adsorpsi Gas Karbonmonoksida (CO) dan Penjernihan Asap Kebakaran Menggunakan Karbon Aktif dari Tempurung Kelapa Termodifikasi $\mathrm{TiO}_{2}$.Depok, Program StudiTeknik Kimia, FT-UI.

Guritno, Ario, 2012. Sintesis dan UjiKinerja Katalis Komposit Ag/ $/ \mathrm{TO}_{2}$ - Zeolit Alam Lampung Karbon Aktif Serta Rekayasa Alat untuk Purifikasi Udara Ruang Depok, Program StudiTeknik Kimia, FT-UI.

Maryanto, Dicky, Mulasari, Asti Surahma dan Suryani, Dyah, 2009. Penurunan Kadar Emisi Gas Buang Karbonmonoksida (CO) dengan Penambahan Arang Aktif pada Kendaraan Bermotor di Yogyakarta, Jurnal KES MAS.3 (3): 162-232.

Meisrilestari, Yessy, 2013.PembuatanArangAktif Dari Cangkang Kelapa Sawit Dengan 
Aktivasi Secara Fisika, Kimia Dan FisikaKimia, Konversi, 2. 1

Notoatmodjo, Soekidjo, 2012. Metodologi PenelitianKesehatan. Jakarta :RinekaCipta.

Nurbiantara, Setiyawan, 2010. Pengaruh Polusi Udara Terhadap Fungsi Paru pada Polisi Lalu Lintas di Surakarta. Surakarta, FKUNS.

Peraturan Menteri Kesehatan Republik Indonesia Nomor 1077 Tahun 2011 Tentang Pedoman Penyehatan Udara Dalam Ruang Rumah.

Peraturan Pemerintah Republik Indonesia Nomor 41 Tahun 1999 Tentang Pengendalian Pencemaran Udara.
Rahmawati, Novi, 2008. Pola Spasial Konsentrasi Gas Karbonmonoksida (CO) di Kota Jakarta. Depok, Program StudiGeografi, FMIPA-UI.

Saragih, Winda, 2011. Degradasi Polutan Udara Ruangan Menggunakan Lampu Hias dengan Penutup Berlapis Katalis $\mathrm{TiO}_{2}$ Termodifikasi.Depok, Departemen Kimia, FT-UI.

Somad, Raden, 2009. Arang Aktif. http://radensomad.blogspot.com/2009/02/ arang-aktif.html, 16 Januari 2014

Sukir, 2008. Pembuatan Dan Karakterisasi Karbon Aktif Dari Sekam Padi. Depok, Departemen Kimia, FT-UI. 